\title{
Depression, Guilt, and Tibetan Buddhism
}

\author{
Lynn E. O’Connor ${ }^{1 *}$, Jack W. Berry ${ }^{2}$, David J. Stiver ${ }^{3}$, Rachna K. Rangan ${ }^{1,4}$ \\ ${ }^{1}$ The Wright Institute, Berkeley, USA \\ ${ }^{2}$ Samford University, Birmingham, USA \\ ${ }^{3}$ Graduate Theological Union, Berkeley, USA \\ ${ }^{4}$ The Wright Institute, Berkeley, USA \\ Email: "lconnor@wi.edu
}

Received July $1^{\text {st }}$, 2012; revised August $2^{\text {nd }}$, 2012; accepted September $4^{\text {th }}, 2012$

\begin{abstract}
Depression appears to be somewhat epidemic in the modern world. In prior empirical studies we found depression significantly associated with empathy-based guilt, empathic distress, and an overly active or misattributing moral system. In this study, we compared 98 Buddhists, who were primarily Tibetan meditation practitioners to 438 non-Buddhist, non-practicing community adults on a measure of depression along with measures of maladaptive guilt, empathic distress, anxiety and altruism. Our findings demonstrated that practitioners were significantly lower in depression, pathogenic guilt, anxiety, and empathic distress, and significantly higher on agreeableness, conscientiousness, openness to experience and compassionate altruism directed towards strangers. Intensity of practice significantly correlated with positive outcomes. In addition, we found that within the population of Tibetan Buddhist practitioners, those who endorsed the statement that the goal of meditation was other-focused (for the benefit of all sentient beings) were significantly lower in depression, empathic distress, and anxiety, and significantly higher in cognitive empathy (perspective-taking) compared to practitioners whose goal of meditation was self-focused.
\end{abstract}

Keywords: Depression; Resilience; Meditation; Religion; Compassion

\section{Introduction}

After two decades of studying depression and its relationship to empathy based guilt associated with pathogenic cognitions, empathic distress, and both compassionate and pathological altruism, we became interested in examining the experience of Tibetan Buddhists who appear to be resilient and less vulnerable to depression and PTSD. After suffering serious trauma in Tibet, including imprisonment and torture, followed by a stressful escape over the Himalaya, often on foot, and immigration to Nepal and/or India, the Tibetan Buddhists seem to arrive in their new country with minimal symptoms of depression or PTSD. Prior studies have indicated that refugees who have escaped countries where they were imprisoned and/or tortured were likely to exhibit high rates of Post Traumatic Stress Disorder (PTSD) and depression (Mollica et al., 2001; Hollifield et al., 2002). In addition, it has been suggested by cross-cultural experts that immigration itself is strongly associated with episodes of major depressive disorders (Breslau et al., 2011). Therefore, clearly there may be something different about the practice of Tibetan Buddhism, explaining this contrast.

Tibetan Buddhists have been described as exhibiting protecttive factors in various studies, in terms of reactions to stress, and a general psychological wellbeing, skill at emotion regulation, and low levels of depression and anxiety (Sachs et al., 2008). Studies by Holtz, 1998 and Keller et al., 2006 indicate that unlike many other political torture survivors, Tibetans in exile appear relatively resilient and optimistic. Both Sachs et al., 2008 and Keller et al., 2006 hypothesized that something about the Tibetan Buddhist religion, either specific beliefs or practices or both, may serve as a protective factor against vulner-

\footnotetext{
${ }^{*}$ Corresponding author.
}

ability to psychological distress particularly depression, PTSD, and anxiety.

It has also been suggested that this resilient response to traumatic conditions may be attributed to protective factors associated with specific Tibetan Buddhist beliefs; for example Watkins \& Cheung (1995) have suggested that the habitual tendency to see oneself as having suffered less than others, regardless of circumstances may contribute to this positive outcome. In addition, other beliefs that are an integral part of the religion may play an important role. For example, Tibetan Buddhists believe in Karma, whereby prior actions-including actions in past lives-lead to events, something over which a person has no control in terms of the past. Karma is, however, changeable, in accord with a person's current actions of "body, speech and mind.” In this world-view, a better future may be predicted if a person is an active practitioner. The meditation practices commonly used have thus been empirically associated with psychological wellbeing and low levels of depression in general (Marchand, 2012).

Lutz, Brefczynski-Lewis, Johnstone \& Davison, 2008 and Lutz, Slagter, Dunne \& Davidson, 2008 have performed fMRI and EEG studies with experienced Tibetan Buddhist meditators and shown that experienced Tibetan Buddhist mediators record powerful gamma wave activity that is rarely-if ever- detected in non-meditators. These Gamma waves are brain waves oscillating at roughly 40 cycles per second, indicating intensely focused thought. In addition, it is also reported that the meditators enjoy unusual levels of positive emotions and states of brain activity indicating a greater level of neural communication than is ordinary (Jang et al., 2011; Rubik, 2011).

In our prior studies, initially derived from clinical experience, we focused on the relationship between depression and empathy-based guilt, pathogenic beliefs, empathic distress, and both 
pathogenic and compassionate altruism. In clinical cases, the strong correlation between guilt and depression is well known and guilt is included in the formal criteria for major depressive disorder. We particularly focused on survivor guilt broadly defined, (referring to a fear of harming others by surpassing them, sometimes conscious but often outside of conscious awareness) and omnipotent responsibility guilt, or feeling responsible for other's happiness even when one has no power to change another's situation for better or worse and had no responsibility for their problems to begin with. These types of guilt are associated with "imaginary crimes," that is thinking one has harmed someone by committing a crime that essentially never happened (Weiss, 1993). While empathy-based guilt is to some extent universal, from our clinical experience we hypothesized that both survivor guilt and omnipotent responsibility guilt would be significantly associated with depression, and in many studies these hypotheses were supported (O'Connor et al., 1999, 2002, 2011).

Green S, Lambon Ralph MA, Moll J, Deakin JF, Zahn R. (2012) have used functional MRI to study the brains of people with a history of major depression and a control group of people who never had depression and found that when compared to those in the control group, people with a history of depression showed different responses in brain regions associated with guilt (i.e., the subgenual region of the brain) and knowledge of acceptable social behavior (i.e., the anterior temporal lobe). In particular, they have found that in people with a history of depression the anterior temporal lobe and the subgenual region of the brain do not connect as strongly as they do in people who've never been diagnosed with depression and that this "decoupling" only occurs when people prone to depression feel guilty or blame themselves, but not when they feel angry or blame others. These finding could implicate that the "decoupling" observed in the depressed people could reflect the lack of access to details of about what exactly was inappropriate about their behavior when feeling guilty and as a consequence they extend guilt to things they are not responsible for and feeling inappropriate guilt and support the role for self-blame and guilt might play in depression.

Finding what appears to be a protection from vulnerability to anxiety and depression in practitioners of Tibetan Buddhism may have clinical implications. In a religious tradition largely focused on "others" with rituals carried out routinely and specifically "for the benefit of all sentient beings" one might expect to find higher levels of empathy, empathic distress, empathybased guilt and subsequently, depression. On the other hand, it seemed equally possible that factors as briefly described above, such as a belief in Karma, or a conviction that others are suffering more than oneself, in conjunction with a more general belief system grounded in compassion and altruism towards others, beyond friends and close family, the kind of empathy-based guilt we found associated with depression might be minimized.

This study was designed to investigate the associations between depression, anxiety, empathic distress, empathy-based guilt, and both pathological and compassionate altruism in a population of Tibetan Buddhist meditation practitioners, and compare it to a normal non-practicing religiously varied population in the United States.

\section{Method}

\section{Participants}

Two samples were collected for this study. One sample in- cluded 98 practitioners of Tibetan Buddhist contemplation (70.4\% female) who were recruited through advertisements on Tibetan Buddhist listservs connected to the Foundation for the Preservation of the Mahayana Tradition (FPMT) in the United States. Practitioner ages ranged from 18 to 83 years $(M=44.2$, $\mathrm{SD}=16.4)$. The types of Buddhist contemplation practices reported were 31.6 percent Mahayana, 19.4 percent Vajrayana, 8.3 percent Pure Land, and 40.8 percent Other, a combination of traditions, or non-response. Most participants were European American (68.4\%); other ethnic identifications included Asian American/Pacific Islanders (8.2\%), Latin American (5.1\%), African American (2.0\%), and 16.3 percent other ethnicities, mixed, or non-responses. The sample was generally highly educated, with 16.4 percent of participants having a doctoral degree, 29.6 percent a masters degree, 18.4 percent a bachelors degree, 26.4 percent with some college education at an undergraduate or graduate level, and the remaining 9 percent with a high school education or non-response.

The other sample, which served as a comparison group, included 438 adult participants (83\% female) recruited through advertisements on Craigslist. Of 450 initial participants, 12 who identified as Buddhists were excluded from the sample. Participant ages ranged from 18 to 72 years $(M=30.5, S D=11.1)$. Ethnic identities were as follows: European American (51\%), Asian American/Pacific Islanders (15.3\%), Latin American (3\%), African American (2.3\%), and 28.4 percent other ethnicities, mixed, or non-responses. Education levels of participants were as follows: 3.3 percent had doctoral degrees, 14 percent masters degrees, 32.6 bachelors degrees, 39.7 percent with some college education at an undergraduate or graduate level, and the remaining 10.4 percent with a high school education or less or non-response.

\section{Instruments}

The Center for Epidemiologic Studies Depression Scale (CESD; Radloff, 1977) is a widely-used 20-item self-report instrument that assesses symptoms associated with depression. Items are scored on a 4-point scale to indicate how often symptoms are experienced in the preceding week. Scores range from 0 to 60. Higher scores indicate higher levels of depression. Alpha coefficients have ranged from .84 to .90 (Radloff, 1977).

The Interpersonal Guilt Questionnaire-67 (IGQ-67; O’Connor, Berry, Weiss, Bush \& Sampson, 1997) is a 67-item measure, using Likert-type scales, to assess empathy-based guilt. Three subscales were used in this study. Survivor Guilt is characterized by the belief that being successful or happy will make others feel inadequate simply by comparison (e.g., "It makes me very uncomfortable to receive better treatment than the people I am with"). Separation Guilt is characterized by the belief that if a person separates from, leads his or her own life, or differs from loved ones in some way, he or she will cause loved ones to suffer (e.g. "I am reluctant to express an opinion that is different from the opinions held by my family or friends"). Omnipotent Responsibility Guilt is characterized by the belief that one is responsible for the happiness and wellbeing of others (e.g. "I often find myself doing what someone else wants me to do, rather than doing what I would most enjoy”). Internal consistencies (Cronbach's alpha coefficients) for the subscales have ranged from .76 to .85 for Survivor/Outdoing Guilt, from .84 to .89 for Self-Hate, from .71 to .83 for Omnipotent Responsibility Guilt, and from .73 to .83 for Sepa- 
ration Guilt (O’Connor et al., 1997; O’Connor et al., 1999). The construct validity of the IGQ-67 has been established through correlations with other measures of guilt and psychopathology (O’Connor et al., 1997; O’Connor et al., 1999).

Compassionate Altruism Scale (CAS; O’Connor, Berry, Crisostomo, \& Yi, 2005). The CAS is a 45-item instrument, derived from a measure of social support (Vaux, Riedel, \& Stewart, 1987). Instead of measuring how much social support a person received, the CAS measures how much support someone tends to extend to others. Respondents indicate how frequently they perform acts of altruism for family members, friends, and strangers in a variety of social situations. Items from thisquestionnaire include how often the participant "gave money for an indefinite amount of time" and "helped them think about a problem.”

The Interpersonal Reactivity Index (IRI; Davis, 1980) is a 28-item self-report instrument measuring four distinct categories of empathy: Perspective taking (the ability to identify with, or understand cognitively the situation experienced by another person); Empathic Concern (the degree of concern or compassion a person tends to feel on witnessing difficult or unpleasant experiences occurring to another person); Personal Distress (the degree of anxiety or distress a person is likely to feel upon witnessing difficulties experienced by another person); and Empathic Fantasy (the tendency to identify with fictional characters in novels, films, and plays). Davis (1983) reported internal consistencies of the IRI subscales ranging from .71 to .77.

The Big Five Inventory (BFI; John, Donahue, and Kentle, 1992) is a 44-item measure of the Big-Five personality factors: neuroticism, extraversion, agreeableness, conscientiousness, and openness to experience. Short phrases are rated on a 5-point Likert-type scale according to how descriptive the phrases are of the respondent. John et al. (1992) reported internal consistencies for the subscales ranging from .75 to .88 . Peer-peer and peer-self correlations ranged from .21 for agreeableness to .63 for extraversion. Further evidence of construct validity is provided by John, Naumann, and Soto (2008).

\section{Procedure}

Subjects were directed to the study by way of a link provided in the online announcements, where they first read the introductory letter which outlined the anonymous nature of the study, and after which they indicated agreement to participation. From there they went to the study itself, which consisted of the standardized instruments and a demographic questionnaire that included questions about their meditation practices. The questions about the meditation practice included items such as "how long have you been practicing"; "what is the duration of practice during each session" and "what is the main goal for meditation". After completing the survey, they submitted their data, which came into the EPARG server via FileMaker Pro, was then fed into Excel, and from there, was translated into an SPSS file for analysis.

\section{Results}

Independent-samples $t$-tests were used to compare the Tibetan Buddhist practitioners to the non-practitioner comparison group on psychological outcome variables (empathy, empathybased guilt, altruism, depression, and the Big Five personality factors). The results are presented in the Table $\mathbf{1}$.
The practitioners were significantly lower on omnipotent responsibility guilt, empathic distress, and depression. On the Big Five personality factors, the practitioners were significantly higher on agreeableness, conscientiousness, and openness to experience, and they were significantly lower in neuroticism; there was no significant group difference in extraversion. Although the Buddhists did not differ from the comparison group on altruism towards family and friends, they were significantly higher in altruism toward strangers.

Within the Tibetan Buddhist practitioner sample, we assessed the relationships between specific practice variables and psychological outcomes. The practice variables were frequency of meditation, duration of sessions, practice intensity (frequency $\mathrm{X}$ duration), and how long the participant has been meditating. Because the practice variables were ordered categories, we calculated Spearmen rank correlations between these practice variables and psychological outcome variables. The correlations are presented in Table 2.

Measures reflecting frequency and intensity of Tibetan meditation practice tended to be significantly associated with lower psychological distress, including lower depression, neuroticism, empathic distress, and omnipotent responsibility guilt. These practice variables were positively associated with perspective-taking and conscientiousness, but there were no significant associations with the altruism scales. Similar associations were found with number of years meditating.

We also examined whether the practitioners' goals of meditation were related to psychological outcomes. Participant goals were classified as either other-focused (where the goals was for "the benefit of all sentient beings"; $n=37$ ) or self-focused (which included goals such as relaxation, health benefits, enlightenment, to be more positive, or to get out of samsara; $n$ $=39$ ). Independent-samples t-tests were used to compare

Table 1.

Tibetan Buddhist meditation practitioners versus non-practitioners on psychological outcomes.

\begin{tabular}{lccccc}
\hline & \multicolumn{3}{c}{ Buddhists } & \multicolumn{3}{c}{ Non-Buddhists } & \multirow{2}{*}{$\mathrm{t}$} \\
\cline { 2 - 5 } & $\mathrm{M}$ & $\mathrm{SD}$ & $\mathrm{M}$ & $\mathrm{SD}$ & \\
\cline { 1 - 5 } Guilt & & & & & \\
Survivor Guilt & 70.4 & 8.2 & 68.4 & 11.2 & 1.68 \\
$\quad$ Separation Guilt & 36.8 & 7.5 & 37.6 & 8.8 & -.75 \\
$\quad$ Omnipotent Guilt & 45.2 & 7.5 & 47.6 & 8.0 & $-2.68^{* *}$ \\
Empathy & & & & & \\
Perspective-Taking & 26.1 & 4.2 & 25.3 & 4.9 & 1.39 \\
Empathic Concern & 28.2 & 3.7 & 27.9 & 4.2 & .81 \\
Empathic Distress & 15.2 & 4.8 & 17.2 & 5.3 & $-3.38^{* * *}$ \\
Altruism & & & & & \\
Altruism to Family & 174.1 & 29.2 & 170.2 & 32.0 & 1.08 \\
Altruism to Friends & 171.0 & 26.4 & 173.9 & 28.1 & -.91 \\
Altruism to Strangers & 111.9 & 33.1 & 91.9 & 31.9 & $5.40^{* * *}$ \\
Depression (CESD) & 13.2 & 10.6 & 21.7 & 13.2 & $-4.83^{* * *}$ \\
Personality & & & & & \\
Extraversion & 26.3 & 6.4 & 25.6 & 7.1 & .93 \\
Agreeableness & 35.4 & 5.5 & 33.4 & 5.6 & $3.03^{* *}$ \\
Conscientiousness & 34.4 & 6.1 & 31.3 & 6.5 & $4.27^{* * *}$ \\
Neuroticism & 20.7 & 6.0 & 25.4 & 6.7 & $-6.20^{* * *}$ \\
Openness & 41.0 & 6.5 & 39.4 & 6.1 & $2.34^{*}$ \\
\hline
\end{tabular}

Note: ${ }^{*} p<.05,{ }^{* *} p<.01,{ }^{* * *} p<.001$. 
Table 2.

Correlations between psychological outcomes and meditation practices among Tibetan Buddhist practitioners.

\begin{tabular}{lcccc}
\hline & $\begin{array}{c}\text { Frequency of } \\
\text { Meditation }\end{array}$ & $\begin{array}{c}\text { Duration of } \\
\text { Sessions }\end{array}$ & $\begin{array}{c}\text { Practice } \\
\text { Intensity }\end{array}$ & $\begin{array}{c}\text { How Long } \\
\text { Meditating }\end{array}$ \\
\hline Guilt & & & & \\
Survivor Guilt & -.09 & .03 & -.05 & .06 \\
Separation Guilt & -.05 & $-.26^{*}$ & -.15 & -.17 \\
Omnipotent Guilt & $-.30^{*}$ & -.19 & $-.26^{*}$ & $-.28^{*}$ \\
Empathy & & & & \\
Perspective-Taking & $.26^{*}$ & $.26^{*}$ & $.32^{*}$ & $.35^{* *}$ \\
Empathic Concern & .05 & .02 & .07 & -.02 \\
Empathic Distress & $-.39^{* *}$ & $-.30^{*}$ & $-.43^{* *}$ & $-.28^{*}$ \\
Altruism & & & & \\
Altruism to Family & .03 & -.05 & -.05 & -.17 \\
Altruism to Friends & .03 & -.11 & -.05 & -.16 \\
Altruism to Strangers & .14 & .01 & .09 & .13 \\
Depression (CESD) & $-.44^{* *}$ & $-.33^{*}$ & $-.45^{* *}$ & $-.24^{*}$ \\
Personality & & & & .20 \\
Extraversion & .11 & .21 & .09 & .02 \\
Agreeableness & .14 & .15 & .18 & .14 \\
Conscientiousness & .23 & $.37^{* *}$ & $.32^{*}$ & $.26^{*}$ \\
Neuroticism & $-.35^{* *}$ & $-.28^{*}$ & $-.36^{* *}$ & -.22 \\
Openness & .20 & $.31^{*}$ & $.28^{*}$ & .20 \\
\hline
\end{tabular}

Note: ${ }^{*} p<.05,{ }^{* *} p<.01$.

participants with these two classes of goals on all psychological outcomes. Results are provided in Table 3.

Compared to practitioners whose goal of meditation was self-focused, those whose goals were other-focused were significantly lower in depression, empathic distress, and neuroticism, and they were significantly higher in perspective-taking; their lower omnipotence guilt closely approached significance ( $p=.053)$. There were no significant group differences on the altruism scales.

\section{Discussion}

These results support the hypothesis that people who are practicing Tibetan Buddhist meditation tend to experience less depression, anxiety, empathic distress, and empathy-based guilt, that is specifically guilt that occurs when someone is unrealistically worried about harming others by surpassing them, or otherwise blaming themselves for problems of others for which the guilt-ridden person has neither the power to bring on nor the power to alleviate. This type of "omnipotent guilt" involves faulty cognitions and particularly those connected to attributions for harm. The finding that Tibetan Buddhist practitioners are significantly less depressed and less irrationally responsible and self-blaming may be the result of better affect regulation, secondary to meditation practice, or it may be the result of beliefs embedded in the religion. Future research may illuminate this further.

The finding that practicing Tibetan Buddhist meditators demonstrate greater altruism towards strangers may be particu-
Table 3.

Goal of meditation practice and psychological outcomes.

\begin{tabular}{|c|c|c|c|c|c|}
\hline & \multicolumn{2}{|c|}{ Self-Focused } & \multicolumn{2}{|c|}{ Other-Focused } & \multirow{2}{*}{$\mathrm{t}$} \\
\hline & M & SD & M & SD & \\
\hline \multicolumn{6}{|l|}{ Guilt } \\
\hline Survivor Guilt & 70.4 & 7.6 & 70.7 & 7.8 & -.16 \\
\hline Separation Guilt & 37.3 & 8.6 & 35.4 & 6.7 & 1.07 \\
\hline Omnipotent Guilt & 45.8 & 6.5 & 42.7 & 7.0 & 1.97 \\
\hline \multicolumn{6}{|l|}{ Empathy } \\
\hline Perspective-Taking & 25.3 & 4.3 & 27.4 & 4.0 & $-2.02^{*}$ \\
\hline Empathic Concern & 28.4 & 3.7 & 28.8 & 3.6 & .93 \\
\hline Empathic Distress & 16.0 & 4.9 & 13.5 & 3.7 & $2.39^{*}$ \\
\hline \multicolumn{6}{|l|}{ Altruism } \\
\hline Altruism to Family & 171.6 & 32.5 & 175.3 & 26.8 & -.51 \\
\hline Altruism to Friends & 169.9 & 26.7 & 175.3 & 26.9 & -.11 \\
\hline Altruism to Strangers & 110.2 & 29.6 & 119.7 & 33.2 & -1.24 \\
\hline Depression (CESD) & 15.1 & 12.7 & 9.9 & 7.3 & $2.10^{*}$ \\
\hline \multicolumn{6}{|l|}{ Personality } \\
\hline Extraversion & 26.4 & 6.6 & 26.7 & 6.5 & -.21 \\
\hline Agreeableness & 35.2 & 5.4 & 36.5 & 5.1 & -1.06 \\
\hline Conscientiousness & 35.0 & 5.7 & 35.9 & 5.9 & -.67 \\
\hline Neuroticism & 22.2 & 6.1 & 18.2 & 5.2 & $-2.92^{* *}$ \\
\hline Openness & 39.7 & 7.9 & 42.3 & 5.5 & -1.55 \\
\hline
\end{tabular}

Note: ${ }^{*} p<.05,{ }^{* *} p<.01,{ }^{* * *} p<.001$.

larly important in these times in which we are rapidly becoming a global family. Neuroscientists such as Davidson and colleagues have studied the meditation practices of Tibetan Monks in the past decade providing increasing evidence for the positive effects of Buddhist contemplative practices on the emotion regulation. In support of this hypothesis, this study finds that the intensity of mediation is significantly associated with lower depression, anxiety, pathological guilt and empathy-distress and with higher conscientiousness, cognitive empathy (empathic perspective-taking) and altruism to strangers. These findings may be in part explained by the Buddhist worldview that we are all impermanent and interdependent and therefore we may be excluded from the possibility of omnipotent responsibility for things we can't control or even necessary influence. In this view, if we assume that no one is entirely permanent or independent and that everyone is interdependent leads to the belief that no one can be liberated until everyone is liberated, and this provides a strong motivation to liberate all sentient beings from suffering without taking on unrealistic and irrational beliefs associated with the causal attributions often seen associated with pathological guilt and altruism.

The Mahayana Buddhists are trained to believe that to be successful, to achieve happiness and wellbeing in this life and in future lifetimes, the ultimate goal is to become a Bodhisattva, a person for whom liberating all sentient beings takes precedence over liberating the self. In this regard, this study finds that most Tibetan Buddhist practitioners chose the goal of mediation "for the benefit of all sentient beings". There is however a subset of the Tibetan Buddhist practitioners in this study who chose other responses as being the most important goal for mediation. We found that level or intensity of meditation correlated with positive outcomes, and that practitioners whose goal was other-focused (i.e. more in-sync with Bodhisattva beliefs) appear to derive more benefits in terms of positive well-being. While we don't yet know the role that conscious 
beliefs or meditation intensity may play in determining the results found in this study, the differences found within the Tibetan Buddhist sample in terms of levels of meditative practice, suggests that the practice itself may provide the explanation we seek, above and perhaps independent of the consciously expressed beliefs held within the religion.

\section{REFERENCES}

Breslau, J., Borges, G., Tancredi, D., et al. (2011). Migration from Mexico to the United States and subsequent risk for depressive and anxiety disorders: A cross-national study. Archives of General Psychiatry, 68, 428-433. doi:10.1001/archgenpsychiatry.2011.21

Davis, M. H. (1983). Measuring individual differences in empathy: Evidence for a multidimensional approach. Journal of Personality and Social Psychology, 44, 113-126. doi:10.1037/0022-3514.44.1.113

Green, S., Lambon Ralph, M. A., Moll, J., Deakin, J. F., \& Zahn, R. (2012). Guilt-selective functional disconnection of anterior temporal and subgenual cortices in major depressive disorder guilt-selective functional disconnection. Archives of General Psychiatry, 1-8. doi:10.1001/archgenpsychiatry.2012.592

Hollifield, M., Warner, T. D., Lian, N., Krakow, B., Jenkins, J. H., Kesler, J., Stevenson, J., \& Westermeyer, J. (2002). Measuring trauma and health status in refugees: A critical review. Journal of the American Medical Association, 288, 611-621. doi:10.1001/jama.288.5.611

Holtz, T. H. (1998). Refugee trauma versus torture trauma: A retrospective controlled cohort study of Tibetan refugees. Journal of Nervous \& Mental Disease, 186, 24-34. doi:10.1097/00005053-199801000-00005

Jang, J. H., Jung, W. H., Kang, D. H., Byun, M. S., Kwon, S. J., Choi, C. H., \& Kwon, J. S. (2011). Increased default mode network connectivity associated with meditation. Neuroscience Letters, 487, 358362. doi:10.1016/j.neulet.2010.10.056

John, O. P., Donahue, E. M., \& Kentle, R. (1992). The big-five inventoryversions $4 a$ and 54. Technical Report, Berkeley, CA: Institute of Personality and Social Research, University of California.

John, O. P., Naumann, L. P., \& Soto, C. J. (2008). Paradigm shift to the integrative big-five trait taxonomy: History, measurement, and conceptual issues. In O. P. John, R. W. Robins, \& L. A. Pervin (Eds.), Handbook of personality: Theory and research (pp. 114-158). New York: Guilford Press.

Keller, A., Lhewa, D., Rosenfeld, B., Sachs, E., Aladjem, A., Cohen, I., Smith, H., \& Porterfield, K. (2006). Traumatic experiences and psychological distress in an urban refugee population seeking treatment services. Journal of Nervous and Mental Disease, 194, 188-194. doi:10.1097/01.nmd.0000202494.75723.83

Lutz, A., Brefczynski-Lewis, J. A., Johnstone, T., \& Davidson, R. J. (2008). Regulation of the neural circuitry of emotion by compassion meditation: Effects of meditative expertise. PLOS ONE, 3, e1897.

Lutz, A., Slagter, H. A., Dunne, J., \& Davidson, R. J. (2008a). Attention regulation and monitoring in meditation. Trends in Cognitive Sciences,
12, 163-169. doi:10.1016/j.tics.2008.01.005

Marchand, W. R. (2012). Mindfulness-based stress reduction, mindfulness-based cognitive therapy, and zen meditation for depression, anxiety, pain, and psychological distress. Journal of Psychiatric Practice, 18, 233-352. doi:10.1097/01.pra.0000416014.53215.86

Mollica, R. F., Sarajlic, N., Chernoff, M., Lavelle, J, Vukovic, I. S., \& Massagli, M. P. (2001). Longitudinal study of psychiatric symptoms, disability, mortality, and emigration among Bosnian refugees, Journal of the American Medical Association, 286, 546-554. doi:10.1001/jama.286.5.546

O’Connor, L. E., Berry, J. W., \& Weiss, J. (1999). Interpersonal guilt, shame, and psychological problems. Journal of Social \& Clinical Psychology, 18, 181-203. doi:10.1521/jscp.1999.18.2.181

O’Connor, L. E., Berry, J. W., Weiss, J., Schweitzer, D., \& Sevier, M. (2001). Survivor guilt, submissive behavior and evolutionary theory: The down-side to winning in social comparison. British Journal of Medical Psychology, 73, 519-530. doi:10.1348/000711200160705

O’Connor, L. E., Berry, J. W., Lewis, T., \& Stiver, D. J. (2011). Empathy-based pathogenic guilt, pathological altruism, and psychopathology. In B. Oakley, A. Knafo, G. Madhavan, \& D. S. Wilson (Eds.), Pathological altruism. Oxford: Oxford University Press. doi:10.1093/acprof:oso/9780199738571.003.0024

O’Connor, L. E., Berry, J. W., Weiss, J., \& Gilbert, P. (2002). Guilt, fear, submission, and empathy in depression. Journal of Affective Disorders, 71, 19-27. doi:10.1016/S0165-0327(01)00408-6

O’Connor, L. E., Berry, J. W., Crisostomo, P., \& Yi, E. (2005). Altruism and empathy-based guilt across five cultures. In G. Fricchione (Ed.), Identifying altruism. Santa Fe, NM: Symposium Conducted at the 34th Annual Conference of the Society for Cross-Cultural Research.

Radloff, L. S. (1977). The CES-D scale: A self-report depression scale for research in the general population. Applied Psychological Measurement, 1, 385-401. doi:10.1177/014662167700100306

Rubik B. (2011). Neurofeedback enhanced gamma brainwaves from the prefrontal cortical region of meditators and non-meditators and associated subjective experiences. The Journal of Alternative and Complementary Medicine, 17, 109-115. doi:10.1089/acm.2009.0191

Sachs, E., Rosenfeld, B., Lhewa, D., Rasmussen, A., \& Keller, A. (2008). Entering exile: Trauma, mental health, and coping among Tibetan refugees arriving in Dharamsala, India. Journal of Traumatic Stress, 21, 199-208. doi:10.1002/jts.20324

Vaux, A., Riedel, S., \& Stewart, D. (1987). Modes of social support: The Social Support Behaviors (SS-B) Scale. American Journal of Community Psychology, 15, 209-237. doi:10.1007/BF00919279

Watkins, D., \& Cheung, S. (1995). Culture, gender, and response bias: An analysis of responses to the self-description questionnaire. Journal of Cross-Cultural Psychology, 26, 490-504. doi:10.1177/0022022195265003

Weiss, J. (1993). How psychotherapy works: Process and technique. New York: Guilford Press. 